\title{
Prognostic impact of previous percutaneous coronary intervention in patients with diabetes mellitus and triple-vessel disease undergoing coronary artery bypass surgery
}

Matthias Thielmann, MD, ${ }^{a}$ Markus Neuhäuser, PhD, ${ }^{b}$ Stephan Knipp, MD, ${ }^{a}$ Eva Kottenberg-Assenmacher, MD, ${ }^{c}$ Anja Marr, ${ }^{\mathrm{b}}$ Nikolaus Pizanis, MD, ${ }^{a}$ Matthias Hartmann, MD, ${ }^{\mathrm{c}}$ Markus Kamler, MD, ${ }^{\mathrm{a}}$ Parwis Massoudy, MD, and Heinz Jakob, MD

Earn CME credits at at http://cme.ctsnetjournals.org
From the Department of Thoracic and Cardiovascular Surgery, ${ }^{a}$ West German Heart Center Essen, Essen, Germany; and the Institute for Medical Informatics, Biometry, and Epidemiology ${ }^{\mathrm{b}}$ and the Department of Anaesthesiology and Intensive Care Medicine ${ }^{\mathrm{c}}$ University Hospital Essen, Essen, Germany.

Read at the 79th Scientific Sessions of the American Heart Association, Chicago, Ill, November 12-15, 2006

Received for publication Feb 6, 2007; revisions received April 10, 2007; accepted for publication April 16, 2007.

Address for reprints: Matthias Thielmann, MD, Department of Thoracic and Cardiovascular Surgery, West-German Heart Center Essen, University Hospital Essen, Hufelandstra $\beta e$ 55, 45122 Essen, Germany (E-mail: matthias.thielmann@uni-due.de).

J Thorac Cardiovasc Surg 2007;134:470-6

$0022-5223 / \$ 32.00$

Copyright (๑) 2007 by The American Association for Thoracic Surgery

doi:10.1016/j.jtcvs.2007.04.019
Objectives: In the current era of stent usage, percutaneous coronary intervention is more frequently performed as the initial revascularization strategy in multivessel disease before patients are finally referred to coronary artery bypass grafting. We sought to determine whether previous PCI has a prognostic impact on outcome in patients with diabetes mellitus and triple-vessel disease.

Methods: Between January 2000 and March 2006, 621 consecutive patients with diabetes mellitus and triple-vessel disease undergoing isolated first-time coronary artery bypass grafting as the primary revascularization procedure (group 1) were evaluated for in-hospital mortality and major adverse cardiac events and compared with 128 patients with diabetes mellitus and triple-vessel disease treated during the same time period with previous percutaneous coronary intervention before coronary artery bypass grafting (group 2 ).

Results: All-cause in-hospital mortality was $2.9 \%$ in group 1 and $7.8 \%$ in group 2 (odds ratio, 2.84; 95\% confidence interval, 1.19-6.68; $P=.02$ ). In-hospital major adverse cardiac events were identified in $6.1 \%$ and $14.1 \%$ (odds ratio, $2.51 ; 95 \%$ confidence interval, 1.32-4.73; $P<.005$ ), respectively. Risk-adjusted multivariate logistic regression analysis of previous percutaneous coronary intervention significantly correlated with in-hospital mortality (odds ratio, 2.87; 95\% confidence interval, 1.29-6.37; $P=.03$ ) and major adverse cardiac events (odds ratio, 2.54; 95\% confidence interval, $1.39-4.62 ; P=.01$ ). After computed propensity score matching based on 12 major preoperative risk factors to control selection bias, conditional regression analysis confirmed previous percutaneous coronary intervention to be associated with all-cause in-hospital mortality (odds ratio, 2.97; 95\% confidence interval, 1.12-7.86; $P=.03$ ) and major adverse cardiac events (odds ratio, 2.46; 95\% confidence interval, $1.18-5.15 ; P=.02$ ) in these patients.

Conclusion: Previous percutaneous coronary intervention before coronary artery bypass grafting in patients with diabetes mellitus and triple-vessel disease independently increases the risk for in-hospital mortality and major adverse cardiac events.

$\mathrm{R}$ andomized control trials ${ }^{1-4}$ and recent real-world registries ${ }^{5-7}$ comparing coronary artery bypass grafting $(\mathrm{CABG})$ surgery with percutaneous coronary intervention $(\mathrm{PCI})$ still support $\mathrm{CABG}$ as the superior revascularization strategy in terms of survival and reintervention rate in multivessel disease and particularly in patients with diabetes mellitus and triple-vessel disease ${ }^{7-9}$ However, in the current era of stent usage, the number of patients with multivessel or triple-vessel disease in whom PCI is initially performed and who might not get the 


\section{Abbreviations and Acronyms}

$\mathrm{CABG}=$ coronary artery bypass grafting

LCOS = low cardiac output syndrome

MACE $=$ major adverse cardiac event

PCI = percutaneous coronary intervention

PMI = perioperative myocardial infarction

option of receiving bypass surgery as their first-choice revascularization treatment is rapidly increasing without any equivalent scientific evidence. Subsequent CABG surgery with previous PCI, however, might not achieve the same excellent results, as thoroughly demonstrated in the literature. We therefore sought to determine whether previous PCI has a prognostic impact on surgical outcome in a single-center, propensity score-matched, and risk-adjusted cohort study, analyzing Bypass Angioplasty Revascularization Investigation-like patients ${ }^{10}$ with diabetes mellitus and triplevessel disease who were finally referred to CABG therapy.

\section{Materials and Methods \\ Study Population}

The patient cohort used for this study was drawn from the West German Heart Center cardiovascular database. This database prospectively collects a comprehensive list of prespecified data points, with more than 1800 data items per patient, in all of the consecutive patients undergoing CABG surgery at our institution, including demographic, clinical, and outcome data.

Within the database, patients were coded as having previous stent implant procedures or not. The reported study cohort was selected according to criteria of the Bypass Angioplasty Revascularization Investigation. ${ }^{10}$ Patients included had diabetes mellitus and triple-vessel coronary artery disease (70\% stenosis) at their initial coronary revascularization therapy. Patients were excluded if they had left main stenosis $(>50 \%)$, were treated within 24 hours of a myocardial infarction, or underwent an emergency, concomitant, or repeat surgical procedure. Patients were classified into one of the 2 groups depending on whether they had no previous PCI procedure (group 1) or a previous PCI procedure as the initial revascularization therapy (group 2) before first-time elective $\mathrm{CABG}$ surgery. The association between previous PCI before $\mathrm{CABG}$ and postoperative in-hospital patient outcome was analyzed. The study was approved by the institutional review board. All of the patients had previously granted permission for use of their medical records for research purposes.

\section{Study End Points and Definitions}

All study end points used in this analysis were prespecified. The primary study end point was all-cause in-hospital mortality. The secondary end point was the major adverse cardiac event (MACE) rate, including perioperative myocardial infarction (PMI), low cardiac output syndrome (LCOS), cardiac death, and sudden cardiac death during the postoperative hospitalization period. An independent review of the medical records of the patients who died after $\mathrm{CABG}$ surgery was performed, and cardiac versus noncardiac cause of death was adjudicated.In-hospital death was defined as death after $\mathrm{CABG}$ during the index hospitalization. A PMI was considered to have occurred if one of the following diagnostic criteria were present: (1) a cardiac troponin I level of greater than $10.5 \mathrm{ng} / \mathrm{mL}$ after CABG, as previously described ${ }^{11}$; (2) a creatine kinase-MB level of 3 times greater than the upper normal level; (3) new persistent ST-segment or T-wave changes (Minnesota code 4-1, 4-2, 5-1, 5-2, or 9-2); or (4) the development of new Q-waves (Minnesota code 1-1-1 to 1-2-7). LCOS was defined as a cardiac index of $2.0 \mathrm{~L} \cdot \min ^{-1} \cdot \mathrm{m}^{-2}$ or less or a systolic arterial pressure of $90 \mathrm{~mm} \mathrm{Hg}$ or less, despite high-dose inotropic support (intravenous dopamine, $\geq 8 \mu \mathrm{g} \cdot \mathrm{kg}^{-1} \cdot \min ^{-1}$; dobutamine, $\geq 6 \mu \mathrm{g} \cdot \mathrm{kg}^{-1} \cdot \mathrm{min}^{-1}$; epinephrine, $>0.1 \mu \mathrm{g} \cdot \mathrm{kg}^{-1} \cdot \mathrm{min}^{-1}$; or norepinephrine, $\left.>0.1 \mu \mathrm{g} \cdot \mathrm{kg}^{-1} \cdot \min ^{-1}\right)$. Death was considered cardiac if it was caused by PMI, significant cardiac arrhythmias, or refractory LCOS. Sudden unexpected death occurring without another explanation was defined as sudden cardiac death.

\section{Perioperative Management}

Surgical revascularization was performed by using standard techniques in all patients, as previously described. ${ }^{12}$ Heparin was administered to achieve an activated coagulation time of greater than 400 seconds and protamine to reverse heparin according to standard practice. Patients who were receiving dual-antiplatelet therapy with aspirin and clopidogrel before surgical intervention were perioperatively managed as follows: (1) maintenance of aspirin therapy until surgical intervention and routine intravenous administration of $500 \mathrm{mg}$ of aspirin within 6 hours after surgical intervention followed by $100 \mathrm{mg} / \mathrm{d}$ thereafter and (2) discontinuation of clopidogrel for a 2- to 5-day window in accordance with the current American College of Cardiology/American Heart Association guidelines by withdrawing clopidogrel 72 hours before surgical intervention at the earliest and restarting it within 48 hours after $\mathrm{CABG}$ at the latest.

\section{Statistical Analysis}

Descriptive statistics are summarized for categoric variables as frequencies (percentages) and compared between groups by using the Pearson $\chi^{2}$ exact test. Continuous variables, expressed as means \pm standard deviation or median and interquartile range $(15 \%-75 \%)$ were compared between groups by using the MannWhitney $U$ test or the Student $t$ test. Univariate and multivariate logistic regression analyses were performed to identify preoperative independent predictors for in-hospital death and MACEs. Those variables identified by means of univariate regression with a $P$ value of .1 or less for at least 1 study end point were added to the multivariate regression model. A propensity score matching (n:m) was performed to control for selection bias as a result of nonrandom assignment to the groups. ${ }^{13}$ To be precise, we estimated propensity scores using logistic regression ${ }^{13}$ based on the following patient characteristics and major preoperative risk factors to calculate propensity scores: age, sex, obesity, hypertension, hyperlipidemia, left ventricular ejection fraction, renal disease, previous myocardial infarction, antiplatelet therapy, chronic obstructive pulmonary disease, peripheral vascular disease, and angina class III or IV. We used the propensity scores for stratification $^{13}$; that is, patients with similar propensity scores were matched into 20 sets (strata) of equal size. Such stratification is 
common in medical research ${ }^{13}$ and is recommended according to the results of Brookmeyer and colleagues. ${ }^{14}$ Based on the stratified data, a conditional logistic regression analysis was used. ${ }^{15}$ All statistical analyses were performed with the SAS System, version 8 (SAS Institute, Inc, Cary, NC).

\section{Results}

The West German Heart Center Cardiovascular Database identified a total of 4853 patients who underwent isolated first-time CABG surgery from January 2000 through March 2006. The following subgroups of patients were excluded according to the study exclusion criteria: (1) patients with 1or 2-vessel disease at the time of recent PCI $(n=351)$ or before CABG surgery ( $\mathrm{n}=1019)$, (2) nondiabetic patients ( $\mathrm{n}=3494)$, (3) patients with left main disease $(\mathrm{n}=1747)$, (4) patients with emergency status $(n=323)$, or (7) patients with acute coronary syndromes $(n=434)$. In addition, 16 patients with incomplete data on PCI status were excluded, leaving 749 patients included for the present study. Of these, 621 patients with diabetes mellitus and triple-vessel disease underwent isolated first-time CABG surgery as the primary revascularization therapy without having had previous PCI in group 1, whereas 128 patients with diabetes mellitus and triple-vessel disease had PCI as the initial revascularization therapy before undergoing isolated firsttime CABG in group 2.

Preoperative characteristics of the patients are shown in Table 1. Patients did not differ according to most of their demographics, risk factors, and comorbidities, except for a significantly higher number of patients with hypertension and a higher number of patients with preexisting renal disease in group 2. Patient groups were also significantly different according to their history of previous myocardial infarctions and of course their history of previous PCI procedures. As a result, more group 2 patients had antiplatelet therapy before surgical intervention with aspirin, clopidogrel, or both compared with group 1 patients. The average time between last PCI and CABG was $8 \pm 11$ months (Table 1). As a main indication for CABG surgery, preoperative coronary angiography presented $15 \%$ of group 2 patients with isolated in-stent restenoses, $25 \%$ with isolated de novo coronary artery stenoses, and $60 \%$ with combined in-stent restenoses and de novo coronary artery stenoses. According to the type of stent used, $72 \%$ of group 2 patients had bare-metal stents, $12 \%$ had drug-eluting stents, and $16 \%$ had both bare-metal stents and drug-eluting stents. Intraoperative results, such as cardiopulmonary bypass and aortic crossclamp times, number of bypass grafts and distal anastomoses, and mean bypass graft flows, did not differ between the groups.

The incidences of the primary and secondary study end points, as well as all other postoperative outcome data, are presented in Figures 1 and 2 and Table 2. As a main result, the 2 study groups were different regarding all-cause in-
TABLE 1. Preoperative patient characteristics

\begin{tabular}{|c|c|c|c|}
\hline & $\begin{array}{c}\text { Group 1, } \\
\text { without previous } \\
\text { PCI (n = 621) }\end{array}$ & $\begin{array}{c}\text { Group 2, } \\
\text { with previous } \\
\mathrm{PCI}(\mathrm{n}=128)\end{array}$ & $P$ value \\
\hline \multicolumn{4}{|l|}{ Demographics } \\
\hline Age (y) & $66 \pm 9$ & $67 \pm 9$ & .44 \\
\hline Sex, female & $165(27)$ & $33(26)$ & .91 \\
\hline Body weight (kg) & $83 \pm 16$ & $83 \pm 13$ & .67 \\
\hline \multicolumn{4}{|l|}{$\begin{array}{l}\text { Risk factors and } \\
\text { comorbidities }\end{array}$} \\
\hline Diabetes mellitus & $621(100)$ & $128(100)$ & 1.00 \\
\hline Dietary treated & $110(18)$ & $26(20)$ & .53 \\
\hline Medically treated & $319(51)$ & $58(45)$ & .24 \\
\hline Insulin treated & $192(31)$ & $43(34)$ & .60 \\
\hline Hypertension & $511(82)$ & $114(85)$ & .07 \\
\hline Hyperlipidemia* & $458(74)$ & $103(80)$ & .12 \\
\hline Obesity (BMI >30) & $333(54)$ & $76(59)$ & .24 \\
\hline Smoking past 2 mo & $89(14)$ & $23(18)$ & .34 \\
\hline Smoking past $1 \mathrm{y}$ & $239(38)$ & $45(35)$ & .49 \\
\hline History of stroke & $73(12)$ & $19(15)$ & .37 \\
\hline COPD & $111(18)$ & $28(22)$ & .32 \\
\hline $\begin{array}{l}\text { Peripheral vascular } \\
\text { disease }\end{array}$ & $109(18)$ & $24(19)$ & .80 \\
\hline Renal disease† & $97(16)$ & $32(25)$ & .01 \\
\hline \multicolumn{4}{|l|}{ Cardiac history } \\
\hline Angina CCS III-IV & $53(9)$ & $9(7)$ & .61 \\
\hline $\mathrm{Ml}>4$ wk prior & $211(34)$ & $57(45)$ & .03 \\
\hline Previous $\mathrm{PCl}$ & $0(0)$ & $219(171)$ & $<.0001$ \\
\hline $\begin{array}{l}\text { Time interval, } \\
\text { PCI-CABG }\end{array}$ & - & $8 \pm 11$ & - \\
\hline LVEF (\%) & $56 \pm 15$ & $56 \pm 13$ & .73 \\
\hline \multicolumn{4}{|l|}{ Medication } \\
\hline Antiplatelet therapy & $333(54)$ & $94(73)$ & $<.001$ \\
\hline$\beta$-Blocker & $449(72)$ & $101(75)$ & .13 \\
\hline Statins & $424(68)$ & $103(80)$ & .08 \\
\hline ACE inhibitor & $415(67)$ & $94(73)$ & .15 \\
\hline Nitrates & $325(52)$ & $66(52)$ & .92 \\
\hline
\end{tabular}

Data are presented as means \pm standard deviation or number (percentage). $P C l$, Percutaneous coronary intervention; $B M I$, body mass index; COPD, chronic obstructive pulmonary disease; CCS, Canadian Cardiovascular Society; $M I$, myocardial infarction; $C A B G$, coronary artery bypass grafting; $\angle V E F$, left ventricular ejection fraction; $A C E$, angiotensin-converting enzyme. *Serum cholesterol level of $200 \mathrm{mg} / \mathrm{dL}$ or greater or low-density lipoprotein level of greater than $130 \mathrm{mg} / \mathrm{dL}$. TSerum creatinine level of greater than $2.0 \mathrm{mg} / \mathrm{dL}$.

hospital death $(P=.02)$ and in-hospital MACEs $(P=.005$, Figure 1). Furthermore, group 2 patients had a higher incidence of all secondary end points, such as sudden cardiac death $(P=.04)$, cardiac death $(P=.006), \operatorname{LCOS}(P=$ $.003)$, and PMI $(P=.002)$, compared with group 1 patients (Figure 2). This was accompanied by a significantly longer length of intensive care unit stay $(P=.04)$ and a higher incidence of postoperative rethoracotomy $(P=.02$, Table 2$)$.

A logistic regression analysis model was constructed to evaluate independent preoperative predictors for death. Sev- 


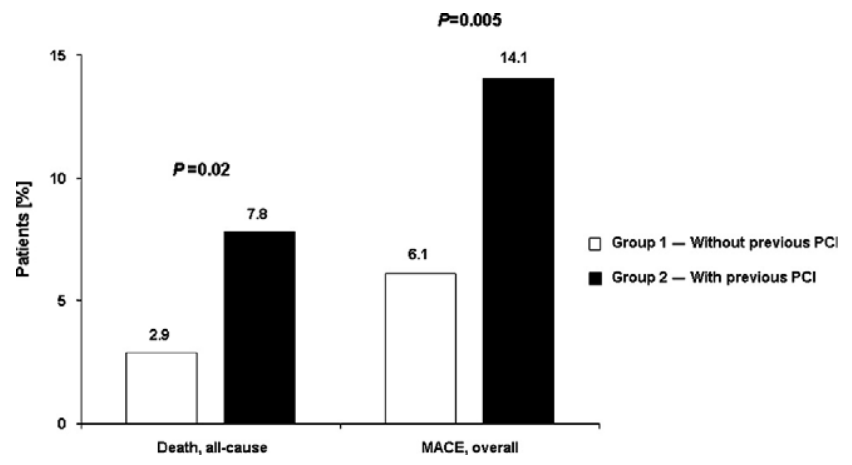

Figure 1. Incidence of death and major adverse cardiac events (MACE) during hospital stay. $P$, Overall significance between the groups.

eral univariate factors were found to be predictive for death (Table 3). After risk adjustment in a multivariate logistic regression model, age and a history of previous PCI were found to be independently associated with in-hospital death (Table 3). As an independent preoperative predictor for in-hospital MACEs, only a history of previous PCI was identified after risk adjustment in the multivariate regression analysis model (Table 4).

In an attempt to further correct for and minimize selection bias, a computed propensity score matching (n:m) of the 2 study groups based on 12 major preoperative risk factors was performed. Even after propensity score matching, a conditional logistic regression analysis confirmed patients with a history of previous PCI to be significantly associated with an increased risk for in-hospital death (odds ratio, 2.97; 95\% confidence interval, 1.12-7.86; $P=.028$ ) and in-hospital MACEs (odds ratio, 2.46; $95 \%$ confidence interval, 1.18-5.15; $P=.016)$.

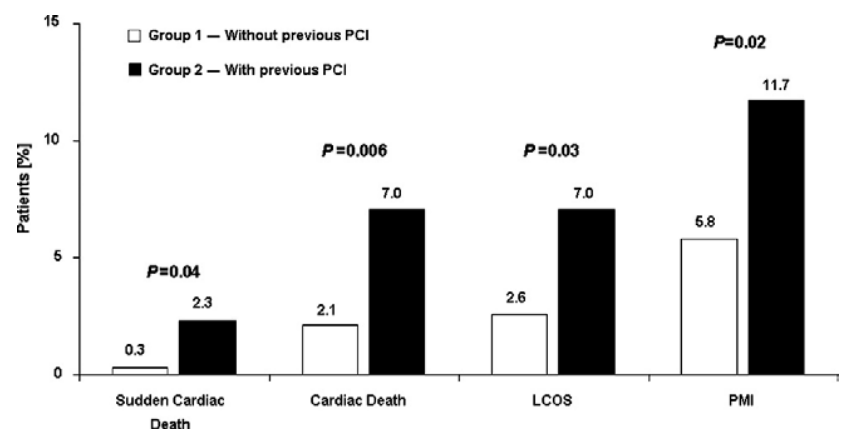

Figure 2. Incidence of secondary end points during hospital stay. $\boldsymbol{P}$, Overall significance between the groups; $\boldsymbol{P C l}$, percutaneous coronary intervention; LCOS, low cardiac output syndrome PMI, perioperative myocardial infarction.

\section{Discussion}

The present study is the first to examine the prognostic impact of previous PCI procedures in the thus-far surgical domain of a high-risk subset of patients with coronary artery disease with diabetes mellitus and triple-vessel disease. The main result of the study is that patients with diabetes mellitus and triple-vessel disease who undergo isolated firsttime elective CABG and were treated initially by means of PCI with coronary stent graft placement carry a higher risk for in-hospital mortality and MACEs compared with the same subgroup of patients without previous PCI before CABG.

Recent randomized controlled trails ${ }^{1-4}$ and large-scale real-world registries ${ }^{5-7}$ of PCI versus CABG performed in the current stent era still support $\mathrm{CABG}$ surgery as the superior and preferred revascularization strategy, deriving a survival benefit for $\mathrm{CABG}$ and reducing the necessity for further coronary reintervention procedures in patients with multivessel disease or left main disease and particularly in patients with diabetes mellitus and triple-vessel disease. ${ }^{16}$

TABLE 2. Intraoperative and postoperative characteristics

\begin{tabular}{|c|c|c|c|}
\hline & $\begin{array}{c}\text { Group 1, } \\
\text { without previous } \\
\text { PCI (n = 621) }\end{array}$ & $\begin{array}{c}\text { Group 2, } \\
\text { with previous } \\
\text { PCI (n = 128) }\end{array}$ & $P$ value \\
\hline \multicolumn{4}{|l|}{ Intraoperative data } \\
\hline CPB time (min) & $109 \pm 36$ & $111 \pm 37$ & .86 \\
\hline ACC time (min) & $70 \pm 23$ & $71 \pm 26$ & .94 \\
\hline Reperfusion time (min) & $34 \pm 16$ & $35 \pm 15$ & .93 \\
\hline No. of grafts & $3.0 \pm 0.8$ & $3.0 \pm 0.9$ & .42 \\
\hline $\begin{array}{l}\text { No. of distal } \\
\text { anastomoses }\end{array}$ & $3.6 \pm 1.2$ & $3.5 \pm 1.3$ & .21 \\
\hline $\begin{array}{l}\text { Mean graft flow (mL/ } \\
\text { min) }\end{array}$ & $54 \pm 31$ & $54 \pm 32$ & .56 \\
\hline \multicolumn{4}{|l|}{ Postoperative data } \\
\hline Ventilation time (h) & $8(7-12)$ & $8(7-11)$ & .95 \\
\hline IABP support & $31(5.0)$ & $8(6.3)$ & .52 \\
\hline ICU stay (d) & $1(1-3)$ & $2(1-4)$ & .04 \\
\hline Hospital stay (d) & $9(7-13)$ & $8(7-12)$ & .34 \\
\hline \multicolumn{4}{|l|}{$\begin{array}{l}\text { Other postoperative } \\
\text { complications }\end{array}$} \\
\hline $\begin{array}{l}\text { Supraventricular } \\
\text { arrhythmia }\end{array}$ & $85(14)$ & $21(16)$ & .41 \\
\hline Ventricular arrhythmia & $30(4.8)$ & $8(6.3)$ & .51 \\
\hline Renal failure (dialysis) & $51(8.2)$ & $12(9.4)$ & .73 \\
\hline Stroke & $12(1.9)$ & $1(0.8)$ & .49 \\
\hline $\begin{array}{l}\text { Re-exploration for } \\
\text { bleeding }\end{array}$ & $14(2.3)$ & $8(6.3)$ & .02 \\
\hline CPR & $18(2.9)$ & $7(5.5)$ & .17 \\
\hline
\end{tabular}

Data are presented as means \pm standard deviation, number (percentage), or median and interquartile range (15\%-75\%). $P C l$, Percutaneous coronary intervention; $C P B$, cardiopulmonary bypass; $A C C$, aortic crossclamp; $I A B P$, intra-aortic balloon pump; ICU, intensive care unit; $C P R$, cardiopulmonary resuscitation. 
TABLE 3. Univariate and multivariate logistic regression analysis of variables associated with all-cause in-hospital death

\begin{tabular}{|c|c|c|c|c|}
\hline & \multicolumn{2}{|c|}{ Univariate analysis } & \multicolumn{2}{|c|}{ Multivariate analysis } \\
\hline & Odds ratio $(95 \% \mathrm{CI})$ & $P$ value & Odds ratio $(95 \% \mathrm{CI})$ & $P$ value \\
\hline Age (y) & $1.1(1.0-1.1)$ & $<.01$ & $1.1(1.0-1.1)$ & .04 \\
\hline Obesity (BMI >30) & $1.0(0.6-1.6)$ & .98 & - & - \\
\hline $\operatorname{LVEF}(\%)$ & $0.9(0.9-1.0)$ & .65 & - & - \\
\hline Peripheral vascular disease & $0.8(0.3-2.4)$ & .70 & - & - \\
\hline Hypertension & $0.9(0.3-3.1)$ & .89 & - & - \\
\hline Hyperlipidemia & $1.2(0.5-3.6)$ & .71 & - & - \\
\hline Angina class III-IV & $1.2(0.5-2.8)$ & .73 & - & - \\
\hline Previous MI & $0.9(0.4-2.0)$ & .71 & - & - \\
\hline Renal disease & $1.4(0.5-3.5)$ & .50 & - & - \\
\hline Group 1, without previous $\mathrm{PCl}$ & Reference & Reference & Reference & Reference \\
\hline
\end{tabular}

$\mathrm{Cl}$, Confidence interval; $B M I$, body mass index; $L V E F$, left ventricular ejection fraction; COPD, chronic obstructive pulmonary disease; $M I$, myocardial infarction; $\mathrm{PCl}$, percutaneous coronary intervention.

Although these findings are conterminously reflected in the current American College of Cardiology/American Heart Association guidelines, which favor CABG surgery over PCI in these patients, substantial variability exists in practice patterns among individual hospitals, suggesting a lack of clinical consensus. Thus, in turn, PCI is currently being performed more often in patients with severe multivessel disease and even in patients with diabetes mellitus and triple-vessel disease who were considered unsuitable in the past. ${ }^{17}$ At the same time, recent randomized clinical trials, ${ }^{1-4}$ although PCI friendly by enrolling only highly selected patient cohorts, ${ }^{18}$ indicate that probably more than $20 \%$ to $40 \%$ of the patients treated by means of PCI with more complex coronary lesions and multivessel disease have symptom recurrence and restenosis, requiring further coronary revascularization therapy. Hence today's CABG surgery is faced with a rapidly and cumulatively increasing number of patients with multivessel disease, in whom previous PCI procedures with coronary stenting have initially been performed before patients are finally referred to $\mathrm{CABG}$ surgery.

The clinical importance and prognostic significance of patients with a history of PCI that might be interfering with outcome when surgical treatment is subsequently required have become recognized recently. At first, evidence emerged in the former times of angioplasty, showing that

Table 4. Univariate and multivariate logistic regression analysis of variables associated with in-hospital MACEs

\begin{tabular}{|c|c|c|c|c|}
\hline & \multicolumn{2}{|c|}{ Univariate analysis } & \multicolumn{2}{|c|}{ Multivariate analysis } \\
\hline & Odds ratio $(95 \% \mathrm{Cl})$ & $P$ value & Odds ratio $(95 \% \mathrm{CI})$ & $P$ value \\
\hline Age (y) & $1.0(1.0-1.1)$ & .02 & $1.0(0.9-1.1)$ & .39 \\
\hline Sex, female & $1.6(0.9-2.9)$ & .09 & $1.4(0.7-2.9)$ & .29 \\
\hline Obesity (BMI >30) & $1.1(0.8-1.4)$ & .51 & - & - \\
\hline LVEF (\%) & $1.0(0.9-1.0)$ & .07 & $1.0(0.9-1.0)$ & .37 \\
\hline Peripheral vascular disease & $1.9(1.0-3.5)$ & .05 & $1.7(0.8-3.5)$ & .18 \\
\hline COPD & $1.1(0.5-2.2)$ & .91 & - & - \\
\hline Hypertension & $2.1(0.6-6.7)$ & .24 & - & - \\
\hline Hyperlipidemia & $1.5(0.7-3.5)$ & .31 & - & - \\
\hline Angina class III-IV & $2.2(1.1-4.6)$ & .03 & $2.0(0.9-4.4)$ & .09 \\
\hline Previous MI & $1.8(1.0-3.2)$ & .04 & $1.7(1.0-3.1)$ & .07 \\
\hline Renal disease & $2.1(1.1-3.9)$ & .02 & $1.6(0.8-3.4)$ & .22 \\
\hline Group 1, without previous $\mathrm{PCl}$ & Reference & Reference & Reference & Reference \\
\hline Group 2, with previous $\mathrm{PCl}$ & $2.5(1.4-4.6)$ & .002 & $2.5(1.2-4.9)$ & .01 \\
\hline
\end{tabular}

$\mathrm{Cl}$, Confidence interval; $B M I$, body mass index; $L V E F$, left ventricular ejection fraction; $C O P D$, chronic obstructive pulmonary disease; $M I$, myocardial infarction; $\mathrm{PCl}$, percutaneous coronary intervention. 
patients with initial percutaneous transluminal coronary angioplasty and subsequently undergoing $\mathrm{CABG}$ had a poorer long-term survival. ${ }^{19}$ There was also recent evidence that PCI itself adversely affects outcome in repeated $\mathrm{PCIs}^{20}$ and also in several clinical studies of noncardiac surgical patients, in whom the risk for major adverse events after surgical intervention significantly increased with previous PCI. ${ }^{21-23}$ More recently, we demonstrated that multiple PCI procedures before CABG significantly impair patient inhospital outcome, ${ }^{12}$ and there is also recent evidence that previous PCI increases the risk of death in the short term, ${ }^{24}$ as well as the risk of symptom recurrence and MACE rate in the midterm, ${ }^{25}$ after coronary bypass surgery. Potential underlying pathomechanisms for MACEs after PCI have been identified, such as several independent predictors and risk factors of early and long-term stent thrombosis, including the use of more than one stent, use of long stents, use of stents placed at a bifurcation, a history of stent thrombosis, incomplete revascularization, diabetes mellitus, renal failure, low ejection fraction, and premature antiplatelet therapy discontinuation, especially after implantation of drugeluting stents. ${ }^{26}$ Conversely, postoperative blood loss and bleeding complications caused by continuation of antiplatelet therapy might lead to increased transfusion and platelet requirements, which in turn might cause acute stent thrombosis. Furthermore, numerous additional perioperative pathomechanisms among patients with previous PCI undergoing CABG might exist, which have been studied less thoroughly and are as yet largely unknown. There is a growing body of evidence that coronary stents are causing arterial wall injury, leading to dysfunctional and denuded coronary endothelium with chronic inflammatory response and platelet and neutrophil adhesion, which in turn are causing adverse cardiovascular events. ${ }^{27-29}$ In addition, if the diameter of the stented vessel is less than 2.5 to $3.0 \mathrm{~mm}$, the risk of thrombosis is much higher, and the bypass graft has to be inserted more distally, which in turn adversely affects coronary run-off and the patency rate of the inserted graft. $^{27,30}$

Although the present study was nonrandomized and retrospective in design and the generalizability of our experience at a single tertiary care medical center might not extend to all CABG-performing clinical centers, as the first study, it clearly indicates that the increasing practice of initial PCI before surgical intervention significantly increases the risk of subsequent CABG in a well-defined risk-adjusted and propensity score-matched subgroup of patients with diabetes mellitus and triple-vessel disease. Further clinical research and multicenter outcome studies are needed to investigate and confirm the short-term and long-term effects of PCI procedures with coronary stenting before CABG surgery.

\section{References}

1. The SoS I. Coronary artery bypass surgery versus percutaneous coronary intervention with stent implantation in patients with multivessel coronary artery disease (the Stent or Surgery trial): a randomised controlled trial. Lancet. 2002;360:965-70.

2. Serruys PW, Ong ATL, van Herwerden LA, Sousa JE, Jatene A, Bonnier JJRM, et al. Five-year outcomes after coronary stenting versus bypass surgery for the treatment of multivessel disease: the final analysis of the Arterial Revascularization Therapies Study (ARTS) randomized trial. $J$ Am Coll Cardiol. 2005;46:575-81.

3. Rodriguez AE, Baldi J, Pereira CF, Navia J, Alemparte M, Delacasa A, et al. Five-year follow-up of the argentine randomized trial of coronary angioplasty with stenting versus coronary bypass surgery in patients with multiple vessel disease (ERACI II). J Am Coll Cardiol. 2005;46: $582-8$.

4. Hoffman SN, TenBrook JA Jr, Wolf MP, Pauker SG, Salem DN, Wong JB. A meta-analysis of randomized controlled trials comparing coronary artery bypass graft with percutaneous transluminal coronary angioplasty: one- to eight-year outcomes. J Am Coll Cardiol. 2003; 41:1293-304.

5. Brener SJ, Lytle BW, Casserly IP, Schneider JP, Topol EJ, Lauer MS. Propensity analysis of long-term survival after surgical or percutaneous revascularization in patients with multivessel coronary artery disease and high-risk features. Circulation. 2004;109:2290-5.

6. Hannan EL, Racz MJ, Walford G, Jones RH, Ryan TJ, Bennett E, et al. Long-term outcomes of coronary-artery bypass grafting versus stent implantation. $N$ Engl J Med. 2005;352:2174-83.

7. Malenka DJ, Leavitt BJ, Hearne MJ, Robb JF, Baribeau YR, Ryan TJ, et al. Comparing long-term survival of patients with multivessel coronary disease after CABG or PCI: analysis of BARI-like patients in Northern New England. Circulation. 2005;112(suppl I):I371-6.

8. Pell JP, Pell ACH, Jeffrey RR, Jennings K, Oldroyd K, Eteiba H, et al. Comparison of survival following coronary artery bypass grafting vs. percutaneous coronary intervention in diabetic and non-diabetic patients: retrospective cohort study of 6320 procedures. Diabet Med. 2004;21:790-2.

9. Ben-Gal Y, Mohr R, Uretzky G, Medalion B, Hendler A, Hansson N, et al. Drug-eluting stents versus arterial myocardial revascularization in patients with diabetes mellitus. J Thorac Cardiovasc Surg. 2006; 132:861-6.

10. Protocol for the bypass angioplasty revascularization investigation. Circulation. 1991;84(suppl V):V1-27.

11. Thielmann M, Massoudy P, Schmermund A, Neuhauser M, Marggraf G, Kamler K, et al. Diagnostic discrimination between graft-related and non-graft-related perioperative myocardial infarction with cardiac troponin I after coronary artery bypass surgery. Eur Heart J. 2005;26: 2440-7.

12. Thielmann M, Leyh R, Massoudy P, Neuhauser M, Aleksic I, Kamler $\mathrm{M}$, et al. Prognostic significance of multiple previous percutaneous coronary interventions in patients undergoing elective coronary artery bypass surgery. Circulation. 2006;114(suppl I):I441-7.

13. D'Agostino RB Jr. Propensity score methods for bias reduction in the comparison of a treatment to a non-randomized control group. Stat Med. 1998;17:2265-81

14. Brookmeyer R, Liang K, Linet M. Matched case-control designs and overmatched analyses. Am J Epidemiol. 1986;124:693-701.

15. Neuhäuser M, Becher $H$. Improved odds ratio estimation by post hoc stratification of case-control data. Stat Med. 1997;16:993-1004.

16. Opie LH, Commerford PJ, Gersh BJ. Controversies in stable coronary artery disease. Lancet. 2006;367:69-78.

17. King SB III, Dangas G, Moses JW. Surgery is preferred for the diabetic with multivessel disease. Circulation. 2005;112:1500-15.

18. Taggart DP. Coronary artery bypass grafting is still the best treatment for multivessel and left main disease, but patients need to know. Ann Thorac Surg. 2006;82:1966-75.

19. Johnson RG, Sirois C, Watkins JF, Thurer RL, Sellke FW, Cohn WE, et al. CABG after successful PTCA: a case-control study. Ann Thorac Surg. 1995;59:1391-6.

20. Arjomand H, Willerson JT, Holmes J, Bamlet WR, Surabhi SK, Roukoz B, et al. Outcome of Patients With Prior Percutaneous Revas- 
cularization Undergoing Repeat Coronary Intervention (from the PRESTO trial). Am J Cardiol. 2005;96:741-6.

21. Kaluza GL, Joseph J, Lee JR, Raizner ME, Raizner AE. Catastrophic outcomes of noncardiac surgery soon after coronary stenting. $J \mathrm{Am}$ Coll Cardiol. 2000;35:1288-94.

22. Wilson SH, Fasseas P, Orford JL, Lennon RJ, Horlocker T, Charnoff $\mathrm{NE}$, et al. Clinical outcome of patients undergoing non-cardiac surgery in the two months following coronary stenting. J Am Coll Cardiol. 2003;42:234-40.

23. Vicenzi MN, Meislitzer T, Heitzinger B, Halaj M, Fleisher LA, Metzler $\mathrm{H}$. Coronary artery stenting and non-cardiac surgery-a prospective outcome study. Br J Anaesth. 2006;96:686-93.

24. Hassan A, Buth KJ, Baskett RJ, Ali IS, Maitland A, Sullivan JA, et al. The association between prior percutaneous coronary intervention and short-term outcomes after coronary artery bypass grafting. Am Heart $J$. 2005;150:1026-31.

25. Gurbuz AT, Zia AA, Cui H, Sasmazel A, Ates G, Aytac A. Predictors of mid-term symptom recurrence, adverse cardiac events and mortality in 591 unselected off-pump coronary artery bypass graft patients. J Card Surg. 2006;21:28-34.

26. Iakovou I, Schmidt T, Bonizzoni E, Lei G, Sangiorgi G, Stankovic $\mathrm{G}$, et al. Incidence, predictors, and outcome of thrombosis after successful implantation of drug-eluting stents. JAMA. 2005;293: 2126-30

27. Gomes WJ, Buffolo E. Coronary stenting and inflammation: implications for further surgical and medical treatment. Ann Thorac Surg. 2006;81:1918-25.

28. Hofma SH, van der Giessen WJ, van Dalen BM, Lemos PA, McFadden EP, Sianos G, et al. Indication of long-term endothelial dysfunction after sirolimus-eluting stent implantation. Eur Heart J. 2006;27: 166-70.

29. Lerman A, Zeiher AM. Endothelial function: cardiac events. Circulation. 2005;111:363-8

30. Gaudino M, Cellini C, Pragliola C, Trani C, Burzotta F, Schiavoni G, et al. Arterial versus venous bypass grafts in patients with in-stent restenosis. Circulation. 2005;112(suppl I):I265-9. 